\title{
MANAGEMENT OF MEDIA ORGANIZATIONS (RADIO AND TV) WITH SPECIAL EMPHASIS ON KNOWLEDGE MANAGEMENT
}

\author{
Zahra Dastgheyb Shirazi \\ MA in Social Communication, Islamic Azad University, Central Tehran Branch
}

\begin{abstract}
It seems that the most appropriate method to prevent deterioration and continue surviving is to increase information and dissemination of knowledge between employees of different levels of organization. Because knowledge is one of the most important and most valuable asset of any organization. The aim of this study is to examine the management of media organizations (radio and TV) with special emphasis on knowledge management. The research method was a descriptive correlational and the study population included all employees of media organizations (radio, television, press, etc.) in Tehran city and 150 employees and managers were selected and analyzed by using available sampling method. The data collection tool is a questionnaire in this study. The data obtained were analyzed through questionnaires using SPSS software and Pearson and regression statistical tests. In general, the results showed that the use of knowledge management, knowledge preservation, knowledge transfer, knowledge creation, knowledge application has positive and significant impact on the management of media organizations.
\end{abstract}

Keywords: media, radio, television, knowledge management

\section{PROBLEM STATEMENT}

Steve Hulse (2001) introduced the concept of knowledge management in relation to the concepts of data, information and knowledge. He believes that the main problem in the field of knowledge management is that organizations do not know how to convert data into information and information into knowledge; therefore, many organizations remained at the level of data management and information management.Hulse argues that knowledge management is a process through which organizations gain the ability to convert data into information and information into knowledge and in addition, they can use this achieved knowledge in order to make better and more effective decisions.

Haynes (2001) argues that knowledge management is a process based on four pillars. Content: that relates to the type of knowledge (explicit or implicit), skills: achieving the skills to extract knowledge, culture: organizational culture should encourage the distribution of information, organize: organizing the existing knowledge.

Malhotra (2004) defines knowledge management as such: "Knowledge management is a process through which organizations acquire skills in the field of learning (internal knowledge) coding knowledge (external knowledge) and distribute knowledge."

Karl Wiig (2002) argues that knowledge management means creating the needed processes to identify and capture data, information and knowledge required by the organization from the internal and external environment and transform them into decisions and actions of organizations and individuals.

Organizational Knowledge Management is one of the most important success factors for companies in competitive conditions and the information age. The importance of this issue widens enough for today, so that a number of organizations measures their knowledge and this is reflected as corporate intellectual capital and used to rank between companies (Mousavi, 2005). These institutions believe that implementing knowledge management in the organization, as a part of organizational strategy, is essential (Hassanzadeh, 2006).

In today's competitive environment, organizations need to have a deeply impressive wealth of knowledge compared to the past. Being inimitable, scarcity, valuable and irreplaceable characteristics 
of these knowledge assets, along with the emergence of approaches and concepts such as knowledge management, intellectual capital, intangible assets, knowledge-oriented perspective to the organization and the multitude of academic research and administrative staff, all indicate the importance of knowledge resources in organizations (Anvar and Shahaei, 2009). Davenport and Prusak (1998) believe that knowledge management is a major effort to figure out the hidden assets in the minds of people and convert this hidden treasure to organizational assets, so that a wide range of people can involve in the decision-making and access to this wealth to use it.

Therefore, the aim of this study is to examine the management of media organizations (radio and TV) with special emphasis on knowledge management.

\section{KNOWLEDGE MANAGEMENT}

"The most fundamental characteristic of smart organizations in the twenty-first century is their emphasis on knowledge and information. Unlike the past, today's organizations have advanced technology, and requires acquisition, management and exploitation of knowledge and information in order to efficiently manage and keep track of inexhaustible changes. Knowledge is a powerful tool that can create great changes in the world and the pursuit of innovation (Cheese, 1998).

"The importance of knowledge in today's complex global environment cannot be ignored. All organizations that know how to effectively acquire, distribute and manage, will be the leaders of their industry. We are moving towards an era that competitive advantage not only obtain through access to information, but more importantly it can be achieved through the creation of new knowledge (Davenport, 1997).

"Knowledge management is an interdisciplinary business that deals with all aspects of knowledge creation, encoding, multiplexing and use knowledge to enhance learning and innovation in the context of the company. Knowledge management, is dealing with the current technological tools and organizational methods, including the production of new knowledge, gain valuable knowledge from external sources, the use of this knowledge in decision making, importing knowledge in processes, products and services, information encoding in documents software and databases, facilitating the growth of knowledge, knowledge transfer to other parts of the organization and ultimately measure knowledge assets and impact of knowledge management (Leonard, 1990).

There is no detailed and comprehensive definition regarding the knowledge management. Some experts defined knowledge management as the application of created knowledge (Quintas et al, 1997), while most experts in knowledge management believe that this is a comprehensive management concept, which is a combination of human dimensions, psychology, sociology and technology. In fact, knowledge management allows organizations to distribute ideas, documents and information. In long term, knowledge management can create a unique culture by which knowledge should be considered as a continuous task that is constantly growing and changing. But a more general definition of knowledge management raised by Snowden which is based on clear distinction between tacit and explicit knowledge and consists of identification, optimization and active management of smart investments, which is stored in the form of explicit knowledge in artifacts such as books, etc. or in the form of tacit knowledge in the minds of individuals or groups. Optimization of explicit knowledge is carried out through permanent access to knowledge artifacts and optimization of tacit knowledge is done by creating communities and groups to keep track of various knowledge (Snowden, 2000).

Knowledge management is a new foundation and organizational perspective that changes relationships between employees in an organization, focuses on the chain relationship between knowledge and action and continuously improve organizational efficiency. Useful knowledge is something that leads to an effective and flexible think (Toumi, 2002). To this end, it is important to identify sources of knowledge. Efficient knowledge management can achieved clear and tangible results from resources, develop a culture of knowledge sharing within the organization and solves the issues of the day. Three overall knowledge management activities include: information management, qualitative movement and human movement or human factors (Prusak, 2001). 
Knowledge management is significantly effective in improving the reliability of decision-making processes and the quality of its results and is used to determine the relationships between new information, knowing the facts, learn and determine the system values. Knowledge management helps to facilitate the flow of knowledge and can lead to faster and more effective integration of customer knowledge (Retna \& Tee NG, 2011). Knowledge management also contributes to transparency in the process of integration of knowledge in other groups, such as employees (Change et al, 2010). Once customer relationship management be implemented, knowledge management program can expand current knowledge in relation to the customer (Retna \& Tee NG, 2011).

Knowledge management provides tools, processes and databases to share knowledge to customers and employees. This enables organizations to realize the value of customer knowledge integration and ultimately, it is used to provide superior service to customers. Therefore, employees are more willing to share knowledge, so that they can see the value derived from it (Murry, 2006). Tsong also believes that knowledge management is a process through which organizations employ their own collected data (Tsong, 2009).

\section{THE GENERAL MODEL FOR THE STRUCTURE OF KNOWLEDGE MANAGEMENT}

This model offers a broad view of knowledge management systems and reflects the high dependence of these systems on the interaction between people. According to this model, knowledge management systems are formed by the organization's strategy and therefore how to convert these strategies will facilitate organizational knowledge resources. Users can add their knowledge to the system and in turn, their knowledge be strengthened. Other financial systems and human resources are derived. In addition, the system provides the necessary context for access to this important knowledge and accordingly, access to technical systems is also possible. In such systems, knowledge management, content and information into the system are examined in order to ensure their accuracy, security and access. Therefore, the final application and output of the knowledge management systems is efficient and effective support from the knowledge group (Debowski, 2006). This group consists of end users of priorities and overall knowledge of the organization. More important than anything is that knowledge management systems regardless of their organizational status, creates a close relationship between them. The following figure shows the general structure of the knowledge management systems.

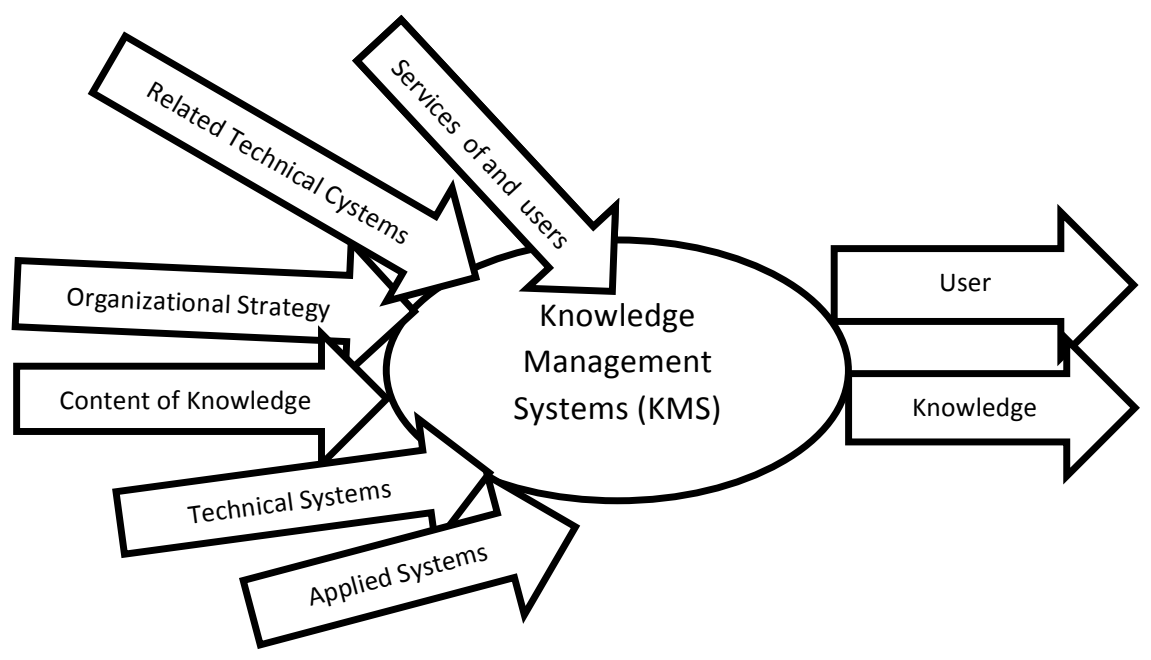

KNOWLEDGE MANAGEMENT PARADIGMS

Due to the interdisciplinary field of knowledge management, the following research and theories reflect two basic paradigms: 


\section{Technological \\ 2. Social - organizational}

The two paradigms are also known as organic and technical - computerized. Organic paradigm focuses on non-computer science disciplines and group dynamics in the environment and raises the importance of human resources organization. In this regard, the interaction between people, business structure, organizational processes and organizational culture are the most important factors. All these factors emphasize the requirement to understand the background and an environment that knowledge management systems are in it. Technical - computerized paradigms deal with the predefined models and assumptions regarding the software and hardware issues. This approach reflects the views of Malhotra (1998) about knowledge. He suggests a static, rational and non-contextual view about the knowledge, which is detected on the basis of mathematical and exploration models. In this approach, there are reference solutions for organizational problems. In addition, the technical - computerized paradigm represents an approach of knowledge that is suitable for the institutionalization of best practices for predictable matters. On the contrary, the organic paradigm (ecological knowledge) represents a dynamic approach that has been associated with diversity and shows a continuous reliability. In such an environment, it must be verified for compliance on the maximization rather than optimization (Hazlt et al., 2005).

\section{RESEARCH BACKGROUND}

Asefzadeh and Fouzounkhah in an article entitled "Knowledge Management: study the factors involved in climbing the ladder of knowledge utilization and division concepts for future research", came to the conclusion that operational measures include the transfer of knowledge, recognition, referral, trying to penetrate and applications that take advantage of the knowledge transfer phase, which is the most critical phase and $30 \%$ of the transmission fail to climb the stairs, the study recommends that all universities and research centers that try to prepare for the application and utilization of research results, should invest in skills acquisition and expertise (Asefzadeh and Fouzounkhah, 2004).

Salehi (2011), in an article entitled "the importance of knowledge management in media organizations" examined the status of knowledge management in radio and improving its quality. $\mathrm{He}$ concluded that knowledge management has not good situation in radio and in the end gave recommendations for its improvement.

Najaf Beigi, R. (2009) in an article titled "learning organization model in the Islamic Republic of Iran Broadcasting" came to the conclusion that IRIB is away from the effective situation of a learning organization and employee performance in team learning and changing in the mental models is more satisfying than managers and other features of the level of learning efforts in two groups are the same. A practical model and practical advice in this regard is proposed In order to reduce the distance to effective conditions and strengthen the required skills in IRIB based on the analysis results and theoretical arguments.

Hashemi (2011), in his thesis, examined the impact of implementation of knowledge management on the economic effectiveness of media (a survey in IRIB). The findings confirmed the effect of knowledge management on the economic effectiveness and this effect was not only significant in terms of development of knowledge. By comparing the results of this study and previous investigations, he found that all dimensions and variables used in these conceptual and analytical models are effective in increasing economic effectiveness.

Irandoust (2015) in a dissertation, entitled "the proposed model of knowledge management for IRIB using the administrators, professors and experts in the IRIB and universities" proposed an applicable native model to this organization. In this regard, 15 managers and professors who are teaching in the field of knowledge management in universities of IRIB, Tehran and Allameh Tabatabaei and are active to carry out projects in this area and in general, were familiar with the area, as well as managers at the IRIB who work somehow with KM, were selected by theoretical sampling method; then, using 
in-depth interviews and mechanisms of underlying theories, the interviews gathered and the data were analyzed in three stages including open coding, axial and selective. After analyzing the interview, 226 concepts were extracted and these concepts were divided in 73 sub-categories, 21 categories and finally 3 axial categories. With open, axial, and selective coding, three-dimensional model in knowledge management can be created in IRIB. The dimensions of this model include "centers and knowledge resources, infrastructure requirements of knowledge management and knowledge management process". The first dimension refers to the knowledge centers in IRIB that knowledge resources are the main focus of knowledge management process. Infrastructure requirements in the form of ten categories refers to the infrastructure necessary for the implementation of knowledge management in IRIB and finally, we reached a process in IRIB, which has 9 element and refers to the effectiveness of knowledge flow in the IRIB.

\section{METHODOLOGY}

The whole objective of this study was to study the role of knowledge management on managing the media organizations. The methodology was descriptive correlational and the statistical population consist of all the staff who are working in the media organizations (radio, television, press, etc.) in Tehran city and 150 employees and managers were chosen and studies by using available sampling method. The data collection tool is a questionnaire in this study. The data obtained were analyzed through questionnaires using SPSS software and Pearson test.

\section{ANALYSIS OF THE RESEARCH FINDINGS}

The main hypothesis: It seems that implementation of knowledge management has a positive and significant effect on the management of media organizations.

Table 1: Pearson correlation coefficient

\begin{tabular}{|c|l|c|c|}
\hline \multicolumn{2}{|c|}{} & $\begin{array}{c}\text { management of } \\
\text { media } \\
\text { organizations }\end{array}$ & $\begin{array}{c}\text { implementation of } \\
\text { imowledge management } \\
\text { knowe }\end{array}$ \\
\hline \multirow{2}{*}{\begin{tabular}{c} 
management of media $\begin{array}{c}\text { organizations } \\
\text { organd }\end{array}$ \\
\multirow{2}{*}{$\begin{array}{c}\text { implementation of } \\
\text { knowledge management }\end{array}$}
\end{tabular}} & Pearson correlation & $\mathbf{1}$ & $\mathbf{. 8 2 5}$ \\
\cline { 2 - 4 } & Significant level. & & $\mathbf{. 0 0 0}$ \\
\cline { 2 - 4 } & Pumber & $\mathbf{1 5 0}$ & $\mathbf{1 5 0}$ \\
\cline { 2 - 4 } & Pearson correlation & $\mathbf{. 8 2 5}$ & $\mathbf{1}$ \\
\cline { 2 - 4 } & Number & $\mathbf{. 0 0 0}$ & $\mathbf{1 5 0}$ \\
\hline
\end{tabular}

Pearson test was used to determine the effect of knowledge management on the management of media organizations. Since the significance level of the test is equal to 0 and less than $1 \%$ and as a result, knowledge management is effective on media organization as much as 99 percent. In addition, the amount of correlation is equal to $(0.825)$ and is positive and this shows that the effect is direct. First secondary hypothesis: It seems that knowledge creation has a positive and significant effect on the management of media organizations.

Table 2: Pearson correlation coefficient

\begin{tabular}{|c|l|c|c|}
\hline \multicolumn{2}{|c|}{} & $\begin{array}{c}\text { management of } \\
\text { media } \\
\text { organizations }\end{array}$ & knowledge creation \\
\hline \multirow{3}{*}{$\begin{array}{c}\text { management of media } \\
\text { organizations }\end{array}$} & Pearson correlation & $\mathbf{1}$ & $\mathbf{. 7 8 6}$ \\
\cline { 2 - 4 } & Significant level. & & $\mathbf{. 0 0 0}$ \\
\cline { 2 - 4 } knowledge creation & Number & $\mathbf{1 5 0}$ & $\mathbf{1 5 0}$ \\
\hline \multirow{3}{*}{\begin{tabular}{l} 
kearson correlation \\
\cline { 2 - 4 }
\end{tabular}} & Significant level. & $\mathbf{. 7 8 6}$ & $\mathbf{1}$ \\
\cline { 2 - 4 } & Number & $\mathbf{1 5 0}$ & $\mathbf{1 5 0}$ \\
\hline
\end{tabular}


Pearson test was used to determine the effect of knowledge creation on the management of media organizations. Since the significance level of the test is equal to 0 and less than $1 \%$ and as a result, knowledge creation is effective on media organization as much as 99 percent. In addition, the amount of correlation is equal to (0.786) and is positive and this shows that the effect is direct.

Second secondary hypothesis: It seems that knowledge preservation has a positive and significant effect on the management of media organizations.

Table 3: Pearson correlation coefficient

\begin{tabular}{|c|c|c|c|}
\hline & & $\begin{array}{c}\text { management of } \\
\text { media } \\
\text { organizations }\end{array}$ & knowledge preservation \\
\hline \multirow{3}{*}{$\begin{array}{l}\text { management of media } \\
\text { organizations }\end{array}$} & Pearson correlation & 1 & $.832^{* *}$ \\
\hline & Significant level. & & .000 \\
\hline & Number & 150 & 150 \\
\hline \multirow{3}{*}{ knowledge preservation } & Pearson correlation & $.832^{* *}$ & 1 \\
\hline & Significant level. & .000 & \\
\hline & Number & 150 & 150 \\
\hline
\end{tabular}

Pearson test was used to determine the effect of knowledge transfer on the management of media organizations. Since the significance level of the test is equal to 0 and less than $1 \%$ and as a result, knowledge transfer is effective on media organization as much as 99 percent. In addition, the amount of correlation is equal to (0.832) and is positive and this shows that the effect is direct.

Third secondary hypothesis: It seems that knowledge preservation has a positive and significant effect on the management of media organizations.

Table 4: Pearson correlation coefficient

\begin{tabular}{|c|l|c|c|}
\hline \multicolumn{2}{|c|}{} & $\begin{array}{c}\text { management of } \\
\text { media } \\
\text { organizations }\end{array}$ & knowledge transfer \\
\hline \multirow{3}{*}{$\begin{array}{c}\text { management of media } \\
\text { organizations }\end{array}$} & Pearson correlation & $\mathbf{1}$ & $\mathbf{. 7 5}^{* *}$ \\
\cline { 2 - 4 } & Significant level. & & $\mathbf{. 0 0 0}$ \\
\cline { 2 - 4 } & Number & $\mathbf{1 5 0}$ & $\mathbf{1 5 0}$ \\
\hline \multirow{3}{*}{$\begin{array}{c}\text { knowledge transfer } \\
\text { Pearson correlation }\end{array}$} & .745 & $\mathbf{1}$ \\
\cline { 2 - 4 } & Significant level. & $\mathbf{. 0 0 0}$ & $\mathbf{1 5 0}$ \\
\cline { 2 - 4 } & Number & $\mathbf{1 5 0}$ & \\
\hline
\end{tabular}

Pearson test was used to determine the effect of knowledge preservation on the management of media organizations. Since the significance level of the test is equal to 0 and less than $1 \%$ and as a result, knowledge preservation is effective on media organization as much as 99 percent. In addition, the amount of correlation is equal to $(0.745)$ and is positive and this shows that the effect is direct.

Forth secondary hypothesis: It seems that knowledge application has a positive and significant effect on the management of media organizations. 
Table 5: Pearson correlation coefficient

\begin{tabular}{|c|c|c|c|}
\hline & & $\begin{array}{l}\text { management of } \\
\text { media } \\
\text { organizations }\end{array}$ & knowledge application \\
\hline \multirow{3}{*}{$\begin{array}{l}\text { management of media } \\
\text { organizations }\end{array}$} & Pearson correlation & 1 & $.885^{* *}$ \\
\hline & Significant level. & & .000 \\
\hline & Number & 150 & 150 \\
\hline \multirow{3}{*}{ knowledge application } & Pearson correlation & $.885^{* *}$ & 1 \\
\hline & Significant level. & .000 & \\
\hline & Number & 150 & 150 \\
\hline
\end{tabular}

Pearson test was used to determine the effect of knowledge application on the management of media organizations. Since the significance level of the test is equal to 0 and less than $1 \%$ and as a result, knowledge application is effective on media organization as much as 99 percent. In addition, the amount of correlation is equal to $(0.885)$ and is positive and this shows that the effect is direct.

\section{CONCLUSION AND RECOMMENDATIONS}

In general, the results showed that the use of knowledge management impact on the management of media organizations. Today, the old ways of managing organizations cannot be responsive to changes in the surrounding environment and uncertainty in organizational environments has increased due to the increasing complexity and speed of developments.

The main purpose of using knowledge management in a variety of institutions is to adapt quickly to the changing environment in order to improve performance.As a result, knowledge management refers to the process of the creation, dissemination and application of knowledge. In other words, the ultimate goal of knowledge management includes knowledge sharing among employees in order to enhance added value in the organization. One of the objectives of knowledge management is to communicate between people who know, so that individual knowledge gradually becomes organizational knowledge.Function or purpose of knowledge management is to promote knowledge among employees. For this purpose, it is necessary to be taught information technology and the major influence in this process should be understood. In fact, the ultimate goal of knowledge management is to increase the organizational intelligence.

In knowledge-based organizations, knowledge is simply transferred to the entire staff. When employees access to corporate knowledge, they can recognize their environment and make it meaningful. They can run things in new and better ways to discover, to work together, to make up for lack of knowledge, boost productivity, customer satisfaction and ultimately can achieve effective competition. Organizations that are trying to generate knowledge through research and development or learning processes are superior than organizations that are working based on the knowledge of others. Knowledge management pays attention to issues such as organizational adaptation, survival and competence in face of increasingly environmental changes. In fact, knowledge management seeks synergistic combination of information processing, information technology and creative ability of human beings.

So, to improve each indicator of knowledge management, the following suggestions are recommended:

Strengthen the potential scientific and value in people; because when people have more knowledge, their resistance to change will be less. Also hire qualified and skilled experts, to provide expertise in the production and delivery of services and use key customers; which means that customers are who always special services, make a clear distinction in the use of knowledge based on strengths and weaknesses. User-friendly working conditions, the use of of knowledge while working; because the employees can acquire the knowledge in a position where they can apply that knowledge 
immediately. Encourage people to use the knowledge and the understanding of the norms and values of the organization's staff.

\section{REFERENCES}

Anvari Rostami, A., Shahaei, B. (2009), Knowledge Management and Learning Organization: Analyzing the Role of documenting knowledge and experience, Journal of Information Technology Management, No. 2, 18-3.

Asefzadeh, S., Fouzounkhah, SH., knowledge management ladder of exploitation of research results, Hormozgan Medical Journal, ninth period, the first issue, Spring 2004: 7-14.

Davenport, T \& L. prusak (1998),Working knowledge: how organizations manage what they Know, Boston: Harvard Business School Press.

Haines, Troy. (2001). The problem of knowledge management, available at: www. Information/ir/ hartly.html.

Hales, steve. ( 2001) . dimensions knowledgeand its management, available at www.insighting.co.uk.

Hashemi, Z. (2011) the impact of implementation of knowledge management on the economic effectiveness of media (a survey in IRIB), master's thesis, Allameh Tabatabaei University, Faculty of Accounting and Management.

Hassanzadeh, M., Fatemi, A., Omrani, E., (2009). "Knowledge Management and Information Science: links and interactions, the Proceedings of the Conference". Tehran: Ketabdar publication Hazlett, S.A, Mcadam, R., Gallagher. S. ( $r \cdots \Delta)$. Theory Building in knowledge management : In

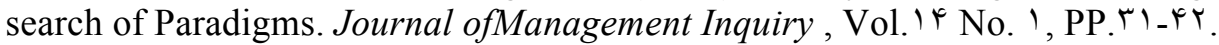

Irandoust, M. (2015), a model of knowledge management for IRIB, Master thesis, University of IRIB, Tehran.

Leonard, D. (199•).Wellsprings of knowledge : building and sustaining the sources of innovation. Boston , MA: Harvard business school press.

Malhotra (2004) Why Knowledge Management Systems Fail? Enablers and Constraints of Knowlege Management in Human Enterprises. In: Koening M.E.D. \& Srikantaiah Kanti (Eds.): Knowledge Management Lessons Learned: What Works and What Doesn't, Information Technology Today, Inc., (American Society for Information Science and Technology Monograph Series), pp. 87-112, 2004.

Mousavi, A. (2005), knowledge management, correcting and training Journal, Issue 46, 12 32 .

Najaf Beigi, R. (2009) provide a model of learning organization in the Islamic Republic of Iran Broadcasting, Cultural Management Journal, third year, No. sitxth.

Prusak, L(2001), "Where did knowledge management come from?". Harvard University IBM. System Journal, Vol. 40, PP. 1002-1007.

Quintas, P. Lefveve, P. and Jones, G(1997), " Knowledge management: a strategic agenda" Long Run Planning . Vol. 30, PP. 5-391.

Renta, S Kala \& Tee NG Pak, (2011), “ Communitis of practice: dynamics and success factors". Leadership \& Organization Development Journal Vol. 32 No. 1, PP.41-59.

Salehi, M. (2011). The importance of knowledge management in media organizations, media studies, the seventh year, No. Eighteen.

Snowden, D(2000), Conference Proceedings, Annual Knowledge Management and Organizational Learning Conference. London: Linkage International.

Toumi, I(2002), “ The Future of knowledge management”. Oxfprd University Life Long Learning in Europe. Vol. 13, PP. 69-79.

Wiig, karl. (1999). The intelligent enterprise and knowledge management, available at: www.ecz.edo. 